\title{
Inhibition of Salmonella Typhimurium adhesion, invasion, and intracellular survival via treatment with methyl gallate alone and in combination with marbofloxacin
}

\author{
Biruk Tesfaye Birhanu', Na-Hye Park', Seung-Jin Lee ${ }^{1}$, Md Akil Hossain² and Seung-Chun Park*i]
}

\begin{abstract}
Salmonella enterica serovar Typhimurium infects intestinal epithelia and macrophages, which is prevented by inhibiting adhesion and cell invasion. This study aimed to investigate the role of methyl gallate (MG) in adhesion, invasion, and intracellular survival of Salmonella Typhimurium in Caco-2 and RAW 264.7 cells via a gentamicin protection assay, confocal microscopy, and quantitative reverse-transcription polymerase chain reaction. MG (30 $\mu \mathrm{g} / \mathrm{mL})$ inhibited adhesion and invasion of Salmonella Typhimurium by $54.01 \%$ and $60.5 \%$ in RAW 264.7 cells, respectively. The combination of MG with sub-minimum inhibitory concentration (MIC) of marbofloxacin (MRB) inhibited the adhesion, invasion, and intracellular survival by $70.49 \%, 67.36 \%$, and $74 \%$, respectively. Confocal microscopy further revealed reductions in bacterial count in Caco-2 cells treated with MG alone or with sub-MIC of MRB. Furthermore, MG alone or in combination with sub-MIC of MRB decreased the motility of Salmonella Typhimurium. Quorum sensing genes including sdiA, srgE, and rck were downregulated by $52.8 \%, 61.7 \%$, and $22.2 \%$, respectively. Moreover, rac- 1 was downregulated by $56.9 \%$ and $71.9 \%$ for MG alone and combined with sub-MIC of MRB, respectively, in mammalian cells. Furthermore, MG downregulated virulence genes of Salmonella Typhimurium including cheY, ompD, sipB, lexA, and $\mathrm{ompF}$ by $59.6 \%, 60.2 \%, 20.5 \%, 31.4 \%$, and $16.2 \%$, respectively. Together, the present results indicate that MG alone or in combination with a sub-MIC of MRB effectively inhibited the adhesion, invasion, and intracellular survival of Salmonella Typhimurium in vitro by downregulating quorum sensing and virulence genes.
\end{abstract}

\section{Introduction}

Salmonella enterica serovar Typhimurium is a gram-negative facultative anaerobic enteric pathogen in humans and animals, and a leading cause of gastroenteritis [1]. The strain invades intestinal phagocytic and epithelial (nonphagocytic) cells. Bacterial adhesion is crucial to cause an infection, enabling the persistence of extracellular bacteria in the host and resulting in the internalization of intracellular bacteria within host cells [2]. Hence, the entry of $S$. enterica into epithelial cells is important

\footnotetext{
*Correspondence: parksch@knu.ac.kr

${ }^{1}$ Laboratory of Veterinary Pharmacokinetics and Pharmacodynamics, College of Veterinary Medicine, Kyungpook National University, Bukgu, Daegu 41566, South Korea

Full list of author information is available at the end of the article
}

for its pathogenicity, intracellular replication, dissemination to other tissues, and establishment of intestinal diseases [3-6].

Salmonella strains penetrate nonphagocytic cells via a trigger or zipper mechanism. The Salmonella pathogenicity island-1 (SPI-1) type III secretion system (T3SS) is critical for invasion of host cells via the trigger mechanism by deploying a macropinocytosisrelated process in enterocytes and the SPI-2 of the T3SS is responsible for the zipper mechanism and intracellular survival of Salmonella Typhimurium [7, 8]. Effector proteins of Salmonella SPI-1 regulate cellular invasion and enable the rearrangement of the actin cytoskeleton in the host cell. These proteins indirectly regulate the activation of the Rho GTPases including the CDC42 and Rac1 proteins in host cells 
$[9,10]$. However, Rck alone can regulate the adhesion and cellular penetration of Salmonella strains via the zipper mechanism [7].

Inhibition of bacterial adhesion, invasion, and intracellular survival significantly limits the pathogenicity of microbial agents and for the prevention and control of infections [11]. Various antimicrobial agents are used to treat intracellular bacterial infections in humans and animals [12]. Fluoroquinolones are among the most common antibiotics used to treat gastroenteritis and are used primarily against multi-drug resistant microbial agents. However, bacteria have developed resistance against these antibiotics. In addition, certain antibiotics at their inhibitory concentration failed to eliminate intracellular surviving bacteria [13].

Ciprofloxacin cannot eliminate intracellular Salmonella even at a higher dosage [14]. Similarly, enrofloxacin, used in veterinary medicine, remained ineffective against intracellular Salmonella. Furthermore, this bacterium has developed resistance to various fluoroquinolones including marbofloxacin (MRB), which is a widely used antibacterial agent in veterinary medicine to treat digestive and respiratory tract infections [15]. This may lead to treatment failure, increased antimicrobial resistance, and increased occurrence of drug failure and cytotoxicity due to frequent, high doses [16, 17]. To overcome these issues, a combination of fluoroquinolone with natural products can serve as a novel therapeutic strategy [13].

Certain naturally occurring phenolic compounds have antioxidant, anticarcinogenic, and antimicrobial activity $[18,19]$. Methyl gallate (MG), a polyphenolic compound with three hydroxyl rings, has anti-inflammatory, antioxidant, anticancer, antiviral, anti-asthmatic, and vasodilating activities [18]. Recently, we reported that MG regulated bacterial quorum sensing (QS) pathways [20]. QS signaling plays a significant role in bacterial metabolism, increase bacterial pathogenicity, and antimicrobial resistance [21]. However, the role of MG in inhibiting bacterial adhesion, invasion, and intracellular survival is unknown.

Hence, we hypothesize that MG reduces the virulence of Salmonella Typhimurium and contributes to the reduction of antibacterial resistance by inhibiting QS signaling when administered alone or in combination with MRB. Therefore, in this study, we investigated the effects and mechanism of the inhibition of Salmonella Typhimurium adhesion, invasion, and intracellular survival in cell cultures via treatment with MG alone and in combination with sub-inhibitory concentration (subMIC) of MRB to combat drug-resistance via downregulation of genes involved in QS signaling.

\section{Materials and methods}

\section{Chemicals, antimicrobials, and reagents}

All chemicals, reagents, and antibiotics used in the experiments were procured from Sigma-Aldrich (Sigma, St. Louis, MO, USA) unless otherwise specified.

\section{Bacteria and cell culture}

Three Salmonella enterica subspecies enterica serovar Typhimurium strains were used. Two field isolates from swine clinical infections, wherein one was susceptible $(0.031 \mu \mathrm{g} / \mathrm{mL})$, while the other was resistant $(0.5 \mu \mathrm{g} / \mathrm{mL})$ to MRB [15]. In addition, ATCC 14028 was used as a control. All the bacteria were grown in Luria-Bertani (LB) broth (Difco, BD, Sparks, MD, USA) at $37{ }^{\circ} \mathrm{C}$ overnight. For the invasion assay, bacteria were cultured in LB broth supplemented with $0.3 \mathrm{M} \mathrm{NaCl}$ in a non-shaking incubator at $37^{\circ} \mathrm{C}$ to induce gene expression. Two cell lines, a macrophage RAW 264.7 cell line and an epithelial Caco-2 cell line, were used for cell culture experiments. RAW 264.7 cells were cultured in RPMI 1640 medium supplemented with $10 \%$ fetal bovine serum (FBS) and $1 \%$ penicillin-streptomycin $(\mathrm{P} / \mathrm{S})$. Caco-2 cells were cultured in minimum essential medium (MEM, Gibco, Grand Island, NY, USA) supplemented with $1 \%$ non-essential amino acids, $20 \% \mathrm{FBS}$, and $1 \% \mathrm{P} / \mathrm{S}$. All cell cultures were incubated at $37{ }^{\circ} \mathrm{C}$ and $5 \% \mathrm{CO}_{2}$.

\section{Cell viability assay}

The effect of MG on the survival rate of the host cell was determined via a 3-(4,5-dimethyl-2-thiazolyl)-2,5-diphenyl-2H-tetrazolium bromide (MTT) assay. Confluent RAW 264.1 cells were seeded in a 96-well plate at a density of $10^{5}$ cells $/ \mathrm{mL}$ and incubated for $24 \mathrm{~h}$ at $37^{\circ} \mathrm{C}$ and $5 \% \mathrm{CO}_{2}$. The medium was aspirated and fresh medium containing a twofold dilution of MG, starting from $2000 \mu \mathrm{g} / \mathrm{mL}$, was added before being incubated overnight at $37{ }^{\circ} \mathrm{C}$ and $5 \% \mathrm{CO}_{2}$. The medium was substituted with fresh medium containing $0.45 \mathrm{mg} / \mathrm{mL}$ of MTT reagent and incubated for $4 \mathrm{~h}$. Finally, dimethyl sulfoxide was added, and the optical density was measured after $5 \mathrm{~min}$ at $570 \mathrm{~nm}$, using a VersaMax ${ }^{\circledR}$ microplate reader (Molecular Devices, Sunnyvale, CA, USA). The test was performed thrice in duplicate. The survival rate was calculated using the following formula:

$$
\text { Survival rate }=\frac{(\text { OD extract }- \text { OD blank })}{(\text { OD control cells }- \text { OD blank })} \times 100
$$

\section{Nitric oxide assay}

The nitric oxide (NO) inhibition test was conducted using RAW 264.7 cells $\left(10^{5}\right.$ cells $\left./ \mathrm{mL}\right)$ in 24-well plates with Griess reagents to confirm the anti-inflammatory activity 
of MG. MG at different concentrations (300, 100, 30, and $10 \mu \mathrm{g} / \mathrm{mL}$ ) was added to the cells $30 \mathrm{~min}$ before inoculation with Salmonella Typhimurium $\left(10^{7} \mathrm{CFU} / \mathrm{mL}\right)$ to make the multiplicity of infection (MOI) 1:100. These mixtures were incubated for $24 \mathrm{~h}$ at $37{ }^{\circ} \mathrm{C}$ and $5 \% \mathrm{CO}_{2}$. The test was conducted using a 96-well plate and twofold serially diluted standard NO starting with $100 \mu \mathrm{M}$ and intact Salmonella and lipopolysaccharide (LPS, $1 \mu \mathrm{g} /$ $\mathrm{mL}$ ) as the positive control; negative control, untreated cells. The test was conducted three times in duplicate and the optical density was measured at $540 \mathrm{~nm}$, using a VersaMax ${ }^{\circledR}$ microplate reader.

\section{Invasion, adhesion, and intracellular killing assay}

The effect of MG alone and in combination with MRB on bacterial invasion was determined using the gentamicin protection assay, as described previously [22], with some modifications. Briefly, MG $(30 \mu \mathrm{g} / \mathrm{mL})$ alone or with subMIC of MRB $(0.015 \mu \mathrm{g} / \mathrm{mL}$ for susceptible and $0.25 \mu \mathrm{g} /$ $\mathrm{mL}$ for resistant bacteria) was added to fully confluent Caco- 2 cells $\left(10^{5}\right.$ cells $\left./ \mathrm{mL}\right)$ and incubated for $30 \mathrm{~min}$. Salmonella Typhimurium $\left(10^{7} \mathrm{CFU} / \mathrm{mL}\right)$ were added and incubated for another $45 \mathrm{~min}$ after being centrifuged at $500 \times g$ for $5 \mathrm{~min}$. Gentamicin $(100 \mu \mathrm{g} / \mathrm{mL})$ was added and incubated for $30 \mathrm{~min}$ before cells were lysed with $0.1 \%$ Triton $^{\circledR} \mathrm{x}-100$ for $10 \mathrm{~min}$. Finally, the suspension was serially diluted and cultured on LB agar plates for viable counting of bacteria after overnight incubation. The same procedure was followed for the adhesion inhibition assay, except for treatment with gentamicin. The experiments were performed at least eight times in duplicate.

Similarly, for the intracellular killing experiment, RAW 264.7 cells $\left(10^{5}\right.$ cells $\left./ \mathrm{mL}\right)$ were cultured in 24-well plates. The cells were treated with Salmonella Typhimurium $\left(10^{7} \mathrm{CFU} / \mathrm{mL}\right)$ and incubated for $45 \mathrm{~min}$ after centrifugation at $500 \mathrm{~g}$ for $5 \mathrm{~min}$. After the cells were washed, MG $(30 \mu \mathrm{g} / \mathrm{mL})$ alone or with sub-MIC of MRB was added and incubated for $1 \mathrm{~h}$ at $37{ }^{\circ} \mathrm{C}$ and $5 \% \mathrm{CO}_{2}$. Finally, cells were treated with gentamicin $(100 \mu \mathrm{g} / \mathrm{mL})$ for $1 \mathrm{~h}$ and lysed with $0.1 \%$ of Triton $\times 100$ before being serially diluted and plated on LB agar.

For all experiments, cells infected with Salmonella Typhimurium without treatment and those treated with sub-MIC of MRB were used as the control.

\section{Confocal microscopy}

Confocal microscopy was performed to visualize and compare the extent of bacterial invasion after treatment with MG. Caco- 2 cells $\left(10^{5}\right.$ cells $\left./ \mathrm{mL}\right)$ were cultured on 12 -mm glass coverslips in 24-well plates, as described previously [23]. Cells were prepared and treated as described above. Cells were gently rinsed once in $0.1 \mathrm{M}$
3-(N-morpholino) propanesulfonic acid (MOPS), $\mathrm{pH}$ 7.2 , containing $1 \mathrm{mM} \mathrm{MgCl}$ ( $\mathrm{MOPS} / \mathrm{MgCl}_{2}$ ). The rinsing solution from the cells was aspirated and $0.5 \mathrm{~mL}$ Live/Dead Staining Solution containing $5 \mu \mathrm{M}$ SYTO9, $30 \mu \mathrm{M}$ propidium iodide (Invitrogen, Thermo Fisher Scientific, Eugene, OR, USA), and $0.1 \%$ saponin in MOPS/ $\mathrm{MgCl}_{2}$ was added. The cells were incubated for $15 \mathrm{~min}$ in the dark at room temperature before rinsing in MOPS/ $\mathrm{MgCl}_{2}$. The coverslips were inverted face down onto glass slides and sealed with clear nail polish. Images were acquired within $30 \mathrm{~min}$, using a Carl Zeiss (LSM700) confocal microscopy.

\section{Motility assay}

Since bacterial motility is critical for its virulence, we sought to determine the effect of MG alone and in combination with sub-MIC of MRB on the motility of Salmonella Typhimurium. The motility assay was conducted in LB medium containing $0.3 \%(\mathrm{~W} / \mathrm{V})$ agar as previously described [24]. Briefly, $5 \mu \mathrm{L}$ of an $8 \mathrm{~h}$ culture of Salmonella Typhimurium was inoculated in medium containing sub-MIC of MRB or MG at 30 or $100 \mu \mathrm{g} / \mathrm{mL}$, respectively, or its combination with sub-MIC of MRB, using medium without treatment as a control. The plates were incubated at $37^{\circ} \mathrm{C}$ for $12 \mathrm{~h}$, and the diameter of bacterial spread was measured using calipers.

\section{Assessment of the expression of genes involved in quorum sensing}

A quorum sensing signaling autoinducer-1 (AI-1) has not been described for Salmonella Typhimurium [25]. Hence, to determine the effect of MG on the expression of QS genes of Salmonella Typhimurium [26], $N$-acyl homoserine lactone (AHL) $(1 \mu \mathrm{mol} / \mathrm{mL})$ was added to $\mathrm{LB}$ broth containing bacteria $\left(10^{7} \mathrm{CFU} / \mathrm{mL}\right)$ and incubated with 30 or $100 \mu \mathrm{g} / \mathrm{mL}$ of MG alone or in combination with sub-MIC of MRB for $8 \mathrm{~h}$. After centrifugation at $13000 \times g$ for $5 \mathrm{~min}$ at $4{ }^{\circ} \mathrm{C}$ the pellet was processed for RNA extraction. Total RNA was extracted using Trizol ${ }^{\circledR}$ (Ambion $^{\circledR}$, Life Technologies, Carlsbad, CA, USA) reagent in accordance with the manufacturer's instructions. RNA purity and concentration were measured using Nanophotometer (Implen GmbH, Munich, Germany). A quantitative reverse transcription-PCR (qRT-PCR) pre-mix (Pioneer, Korea) was used to synthesize cDNA by adding random hexamers to the bacterial RNA. RNA was quantified using a CFX96 Touch $^{\mathrm{TM}}$ real-time PCR detection system (Bio-Rad, Singapore) using $\mathrm{IQ}^{\mathrm{TM}} \mathrm{SYBR}^{\circledR}$ Green supermix for real time PCR (Bio Rad, Singapore). Gene expression levels of $s d i A, r s g E$, and $r c k$ were determined via quantitative reverse transcription polymerase chain reaction (qRT-PCR) Under the following cycling conditions: $95{ }^{\circ} \mathrm{C}$ for $30 \mathrm{~s}$, followed by 40 cycles at $95{ }^{\circ} \mathrm{C}$ 
for $5 \mathrm{~s}, 60{ }^{\circ} \mathrm{C}$ for $30 \mathrm{~s}$, and dissociation at $95{ }^{\circ} \mathrm{C}$ for $15 \mathrm{~s}$, followed by $60{ }^{\circ} \mathrm{C}$ for $30 \mathrm{~s}$. Target gene expression levels were normalized to that of housekeeping gene $\operatorname{rrs} G$ in Salmonella Typhimurium, using the $2^{-\Delta \Delta \mathrm{CT}}$ method.

\section{Gene expression in host cells}

The effect of MG on host gene expression after invasion by Salmonella Typhimurium was also determined via qRT-PCR. Cells were infected with Salmonella Typhimurium, as described for the invasion assay, and total RNA was extracted using Trizol ${ }^{\circledR}$ reagent as described above. cDNA was synthesized using oligo (dT) primers. The conditions for qRT-PCR was set for $95^{\circ} \mathrm{C}$ for $7 \mathrm{~min}$ and 30 cycles of $95{ }^{\circ} \mathrm{C}$ for $30 \mathrm{~s}, 58^{\circ} \mathrm{C}$ for $30 \mathrm{~s}$ and $72{ }^{\circ} \mathrm{C}$ for $1 \mathrm{~min}$. Target gene expression levels were normalized to that of $\beta$-actin (housekeeping gene; internal control), using the $2^{-\Delta \Delta C T}$ method.

\section{Virulence gene expression and total RNA extraction}

To assess virulence gene expression, Salmonella Typhimurium $\left(10^{7} \mathrm{CFU} / \mathrm{mL}\right)$ was incubated in LB broth containing $0.3 \mathrm{M}$ of $\mathrm{NaCl}$ and $\mathrm{MG}$ and $\mathrm{MRB}$ at different concentrations at $37^{\circ} \mathrm{C}$ for $13 \mathrm{~h}$ without agitation. Total RNA was extracted as described above. qRT-PCR for sipB, ompD, ompF, cheY, lexA and rck genes was performed under the following cycling conditions: $95^{\circ} \mathrm{C}$ for 5 min, 40 cycles at $95^{\circ} \mathrm{C}$ for $30 \mathrm{~s}, 60^{\circ} \mathrm{C}$ for $30 \mathrm{~s}, 72^{\circ} \mathrm{C}$ for $1 \mathrm{~min}$ and final annealing and extension of $55^{\circ} \mathrm{C}$ for $5 \mathrm{~s}$ and $95{ }^{\circ} \mathrm{C}$ for $30 \mathrm{~s}$, respectively. The primers used in the study are listed in Additional file 1.

\section{Statistical analysis}

Graphpad prism 7 (GraphPad Software, La Jolla, CA, USA) was used to analyze the results. One-way and twoway analysis of variance (ANOVA) followed by using Tukey's multiple comparison test were used to compare means among the treatment groups and to compute the P-value. Statistical significance was set at $P<0.05$.

\section{Results}

The cytotoxic effect of MG on mammalian cells was determined using Caco-2 and Raw 264.7 cell lines. MG, at its highest concentration $(2 \mathrm{mg} / \mathrm{mL})$, decreased the survival rate of the cells only by $9.5 \%$. The survival rate was increased to $93 \%$, at $62.5 \mu \mathrm{g} / \mathrm{mL}$. Hence, afterwards we used a concentration of $30 \mu \mathrm{g} / \mathrm{mL}$, which yielded a survival rate of $98 \%$ (Figure 1A).

To determine the effect of MG on NO produced by RAW 264.7 cells induced by intact Salmonella Typhimurium, Griess reagent was used. MG displayed dosedependent inhibition of NO induced by the Salmonella Typhimurium strain ATCC 14028 on RAW 264.7 cells. NO levels were reduced by $4.8,33.6,57$, and $76.8 \%$ for cells treated with $10,30,100$, and $300 \mu \mathrm{g} / \mathrm{mL}$ of MG after $24 \mathrm{~h}$ of incubation, respectively (Figure 1B). A significant difference was observed among cells treated with 30, 100, and $300 \mu \mathrm{g} / \mathrm{mL}$ of $\mathrm{MG}$ in comparison with nontreated cells.

The minimum inhibitory concentration (MIC) of MG was determined using the broth micro-dilution method on cation-adjusted Muller Hinton broth (Difco) and RPMI media. After making two-fold dilutions of MG, bacteria at a final density of $10^{5} \mathrm{CFU} / \mathrm{mL}$ was added to the 96 -well plate and incubated for $24 \mathrm{~h}$ at $37^{\circ} \mathrm{C}$. For the

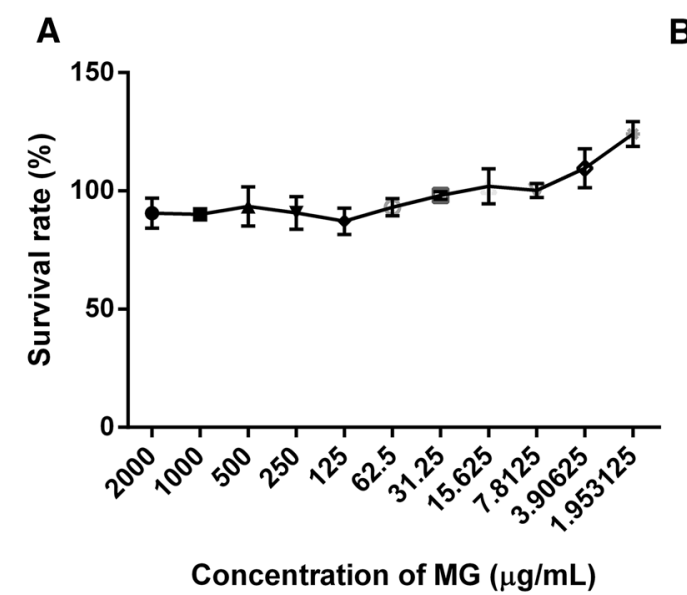

B

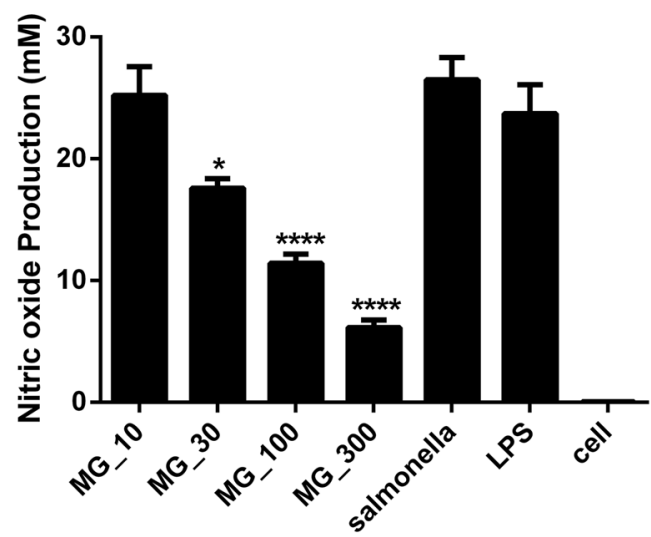

Figure 1 Effect of methyl gallate on cell survival and nitric oxide production in Salmonella Typhimurium (ATCC 14028). A Effect of methyl gallate on cell survival, B methyl gallate inhibited nitric oxide in showing a dose-dependent manner in intact Salmonella Typhimurium in Raw 264.7 cells after $24 \mathrm{~h}$ of incubation. Values indicated are the mean \pm SEM $\left(n=6 ;{ }^{*} P\right.$-value $<0.05 ;{ }^{* *} P$-value $\left.<0.001\right)$. 
three strains tested, we obtained an MIC of $500 \mu \mathrm{g} / \mathrm{mL}$ and at less than $125 \mu \mathrm{g} / \mathrm{mL}$, no bacterial inhibition was observed. Hence, afterwards we used a lower concentration of MG $(30 \mu \mathrm{g} / \mathrm{mL})$, which does not have any antibacterial activity.

Inhibition of bacterial adhesion, invasion, and intracellular survival was assessed using a gentamicin protection assay. MG showed inhibitory activity against adhesion of Salmonella Typhimurium. Adhesion was inhibited by 54.01 and $70.49 \%$ by MG at a concentration of 30 and $100 \mu \mathrm{g} / \mathrm{mL}$, respectively. The combination of sub-MIC of MRB $(0.015 \mu \mathrm{g} / \mathrm{mL})$ and MG $(30 \mu \mathrm{g} / \mathrm{mL})$, however, inhibited $66 \%$ of bacterial adhesion (Figure $2 \mathrm{~A}$ ), whereas, the MIC and sub-MIC of MRB alone inhibited 20.4 and $21.2 \%$, respectively. The inhibition of adhesion by the combination treatment was significantly $(P<0.0001)$ greater than that in the non-treated control group, in a dose-dependent manner.

Similarly, in the invasion assay, MG inhibited 43.75 and $46.4 \%$ of Salmonella Typhimurium at $30 \mu \mathrm{g} / \mathrm{mL}$ alone and in combination with the sub-MIC $(0.015 \mu \mathrm{g} /$ $\mathrm{mL}$ ) of MRB, respectively in Caco- 2 cells. Whereas, the inhibition of invasion by the MIC and sub-MIC of MRB alone was 24.8 and $12.2 \%$, respectively when compared to the non-treated Salmonella Typhimurium. The inhibition increased to 60.5 and $67.36 \%$ in Raw 264.7 cells on using MG alone and in combination with sub-MIC of MRB, respectively (Figures $2 \mathrm{~B}$ and $\mathrm{C}$ ). While, the MIC and sub-MIC of MRB inhibited the invasion of the bacteria in RAW 264.7 cells by only 41.9 and $26.4 \%$, respectively. A significant difference $(P<0.0001)$ was observed in the inhibition of Salmonella Typhimurium invasion by MG alone and its combination with sub-MIC of MRB. However, no significant difference was observed between the assay carried out using Caco-2 and Raw 264.7 cell lines.

MG inhibited invasion in a dose-dependent manner (Figure 2E). Furthermore, no significant difference was observed between the tested ATCC 14028 and two field (resistant and susceptible to MRB) isolates of Salmonella Typhimurium (Figure 2F).

MG also decreased the intracellular-survival of Salmonella Typhimurium alone and in combination with the sub-MIC of MRB. MG decreased the intracellular survival of Salmonella Typhimurium by $45 \%$ and
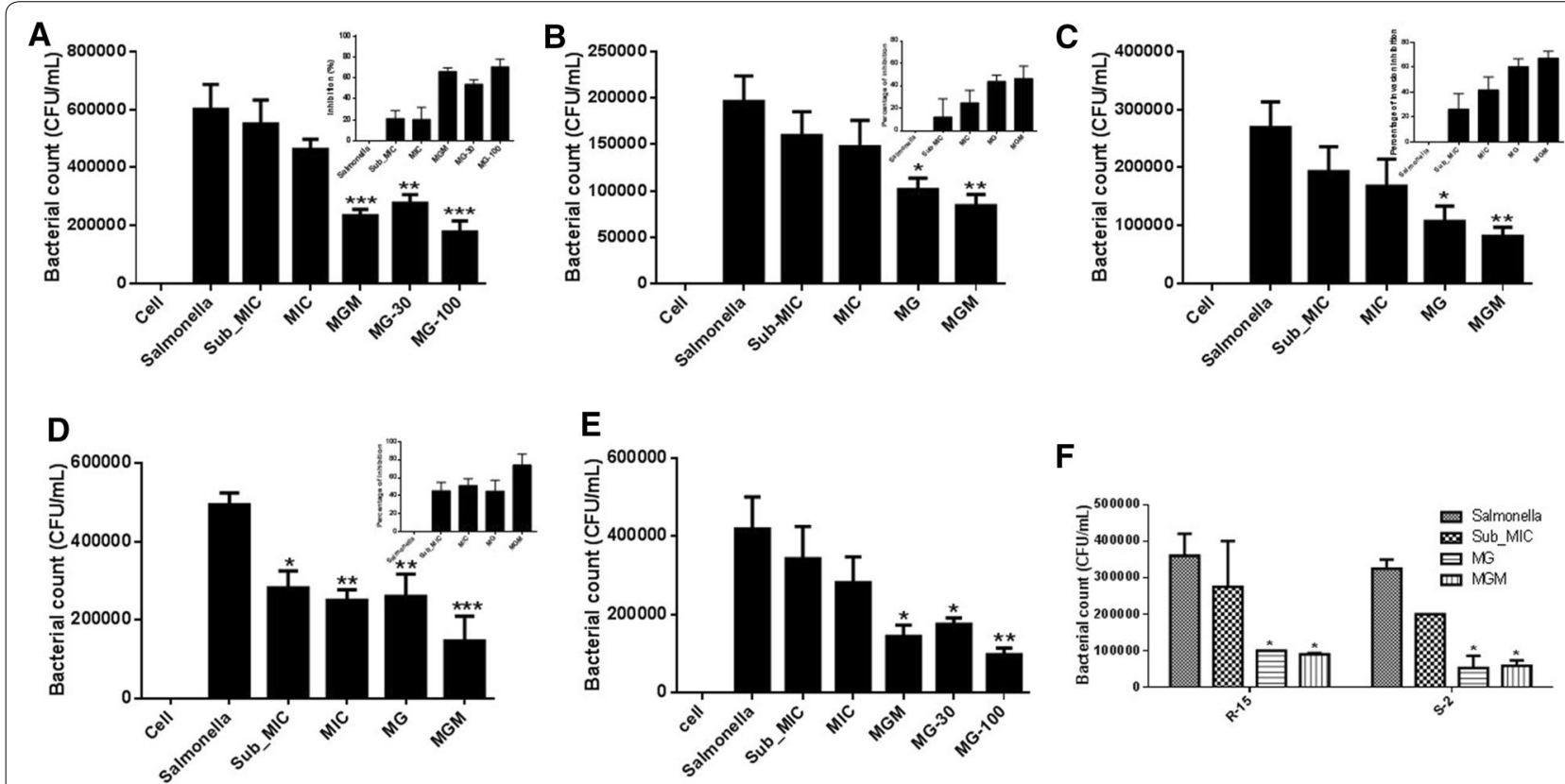

Figure 2 Inhibitory effects of methyl gallate (MG) on adhesion, invasion, and intracellular survival of Salmonella Typhimurium alone and in combination with a sub-minimum inhibitory concentration (MIC) of marbofloxacin (MRB). A Effect of MG alone and in combination with sub-MIC of MRB on adhesion of Salmonella Typhimurium; $\mathbf{B}$ effect of MG alone and in combination with sub-MIC of MRB on the invasion of Salmonella Typhimurium on Caco-2 cells; $\mathbf{C}$ invasion of Raw 264.7 cells, D effect of MG alone and in combination with sub-MIC of MRB on the intracellular survival of Salmonella Typhimurium in Raw 264.7 cells; $\mathbf{E}$ dose-dependent inhibition of invasion by MG; $\mathbf{F}$ inhibition of invasion by MG on two different field isolates of Salmonella Typhimurium. The upper figures show the percentage of inhibition. Cell, uninfected and non-treated control; Salmonella, infected with Salmonella Typhimurium but left untreated; Sub-MIC and MIC, controls treated with the sub-MIC and MIC of MRB; MG-30, treated with $30 \mathrm{\mu g} / \mathrm{mL}$ of methyl gallate alone; MGM, treatment with a combination of methyl gallate $(30 \mu \mathrm{g} / \mathrm{mL})$ and sub-MIC of MRB; MG-100, treated with $100 \mu \mathrm{g} / \mathrm{mL}$ of methyl gallate alone. Results represent the mean \pm SEM $\left(n=8 ;{ }^{*} P\right.$-value $<0.05 ; * *$-value $<0.01$; ***P-value $<0.001)$. 
it suppressed $74 \%$ of the infecting Salmonella Typhimurium in combination with sub-MIC of MRB (Figure 2D); this difference was significant $(P<0.0001)$. The intracellular survival suppression by the MIC and subMIC of MRB was 51.3 and $45.6 \%$, respectively compared with the non-treated Salmonella Typhimurium.

Invading Salmonella Typhimurium in the host cells was confirmed via confocal microscopy. The intracellular bacteria were stained with SYTO-9 and propidium iodide to visualize live and dead cells, respectively. Concurrently, confocal microscopy revealed a reduction in the number of live invading bacteria after treatment with MG alone and in combination with sub-MIC of MRB (Figure 3).

As shown in Figure 4, MG inhibited the motility of Salmonella Typhimurium in all three strains. The zone of Salmonella Typhimurium motility treated with sub-MIC of MRB was 28.5, 19.0, and $14.0 \mathrm{~mm}$ for the ATCC 14028, field susceptible strain (S-2), and resistant strain (R-15), respectively. MG at $30 \mu \mathrm{g} / \mathrm{mL}$ yielded a zone of inhibition of $63.5,69.0$, and $23.0 \mathrm{~mm}$, and at $100 \mu \mathrm{g} / \mathrm{mL}$, the zone was reduced to 23,21 , and $11 \mathrm{~mm}$ against the ATCC 14028 strain, S-2 and R-15 strains, respectively. However, higher inhibition of motility was observed when
MG $(30 \mu \mathrm{g} / \mathrm{mL})$ was combined with sub-MIC of MRB and the growth zone was $8.5,7$, and $5 \mathrm{~mm}$, for the ATCC $14028, \mathrm{~S}-2$, and R-15, respectively. Whereas, the nontreated Salmonella Typhimurium showed a full growth on $90 \mathrm{~mm}$ petri dish (Figure 4).

MG affects QS signaling in bacteria [16]. However, no studies have investigated this inhibition in Salmonella Typhimurium. Since Salmonella Typhimurium has no QS signaling molecule, we treated the bacteria by adding AHL $(1 \mu \mathrm{M} / \mathrm{mL})$ in the LB broth to induce QS signals and determined the effect of MG on the expression of two QS genes of Salmonella Typhimurium, sdiA and $s r g E$. Furanone $(10 \mu \mathrm{g} / \mathrm{mL})$ was used as a positive control. Treatment of Salmonella Typhimurium with $30 \mu \mathrm{g} / \mathrm{mL}$ of MG downregulated $s d i A$ by $52.8 \%$, which was increased to 92.6 and $77.7 \%$ for $100 \mu \mathrm{g} / \mathrm{mL}$ of $\mathrm{MG}$ and its combination with sub-MMIC of MRB, respectively, in the presence of AHL. Whereas, the suppression by the sub-MIC of MRB was $40.6 \%$. $\operatorname{srgE}$ was downregulated by 24.7, 61.7, 93.2, and $79.5 \%$ for Salmonella treated with only subMIC of MRB, 30 of MG alone, $100 \mu \mathrm{g} / \mathrm{mL}$ of MG alone and MG in combination with sub-MIC of MRB, respectively (Figures $5 \mathrm{~A}$ and $\mathrm{B}$ ).
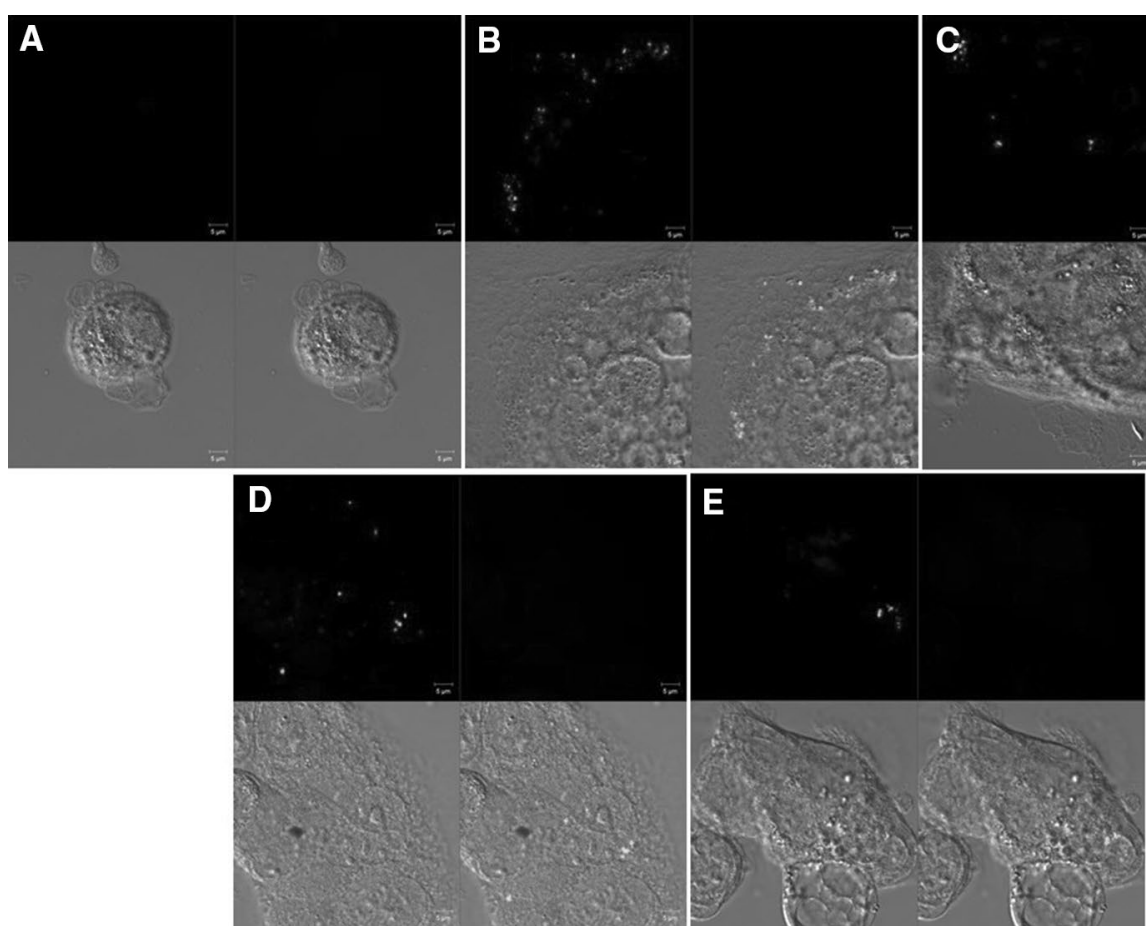

Figure 3 Confocal microscopy of Caco-2 cells infected with Salmonella Typhimurium. A Un-infected cell; B infected with Salmonella Typhimurium but not treated; $\mathbf{C}$ infected with Salmonella Typhimurium and treated with sub-MIC of MRB; $\mathbf{D}$ infected with Salmonella Typhimurium and treated with MG $(30 \mu \mathrm{g} / \mathrm{mL})$ alone; $\mathbf{E}$ infected with Salmonella Typhimurium and treated with a combination of methyl gallate $(30 \mu \mathrm{g} / \mathrm{mL})$ and sub-MIC of MRB. Upper left panel—SYTO-9; upper right panel_PI; lower left panel—cell structure, and lower right panel show merged images. (Red, dead bacteria; Green, Live bacteria; image: ×1000 magnification; representative images of three different experiments are presented). 


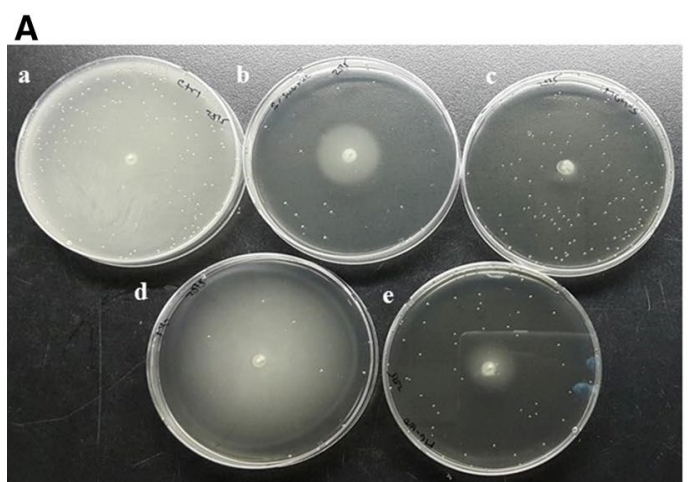

B

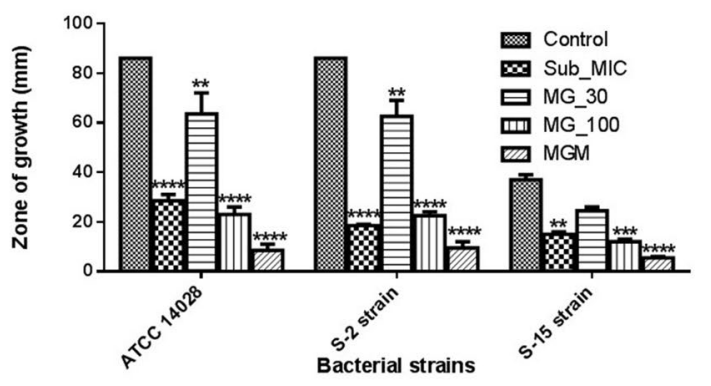

Figure 4 Inhibition of Salmonella Typhimurium motility by methyl gallate alone and in combination with a sub-minimum inhibitory concentration (MIC) of marbofloxacin. A Inhibition of Salmonella motility on semi-solid LB plate, bacteria were inoculated at the center of the LB plate containing $0.3 \%$ agar and incubated for $13 \mathrm{~h}$ at $37^{\circ} \mathrm{C}$. (a) Salmonella Typhimurium inoculated in LB plate containing no antibiotic (b) plate containing sub-MIC of MRB and inoculated with Salmonella Typhimurium, (c) plate containing the combination of MG (30 $\mu \mathrm{g} / \mathrm{mL}$ ) with sub-MIC of MRB and inoculated with Salmonella Typhimurium, (d) plate containing $30 \mu \mathrm{g} / \mathrm{mL}$ of MG and inoculated with Salmonella Typhimurium, and (e) plate containing $100 \mathrm{\mu g} / \mathrm{mL}$ of MG and inoculated with Salmonella Typhimurium. B Inhibition of Salmonella Typhimurium motility in three different strains by MG. Images are representatives of three different experiments. The control comprises Salmonella Typhimurium cultured on agar plates without any drugs; sub-MIC refers agar plate containing sub-MIC of MRB; MG-30 refers to treated with $30 \mu \mathrm{g} / \mathrm{mL}$ of methyl gallate alone; MGM refers to the treatment with a combination of methyl gallate $(30 \mu \mathrm{g} / \mathrm{mL}$ ) and sub-MIC of MRB; MG-100 refers to treated with $100 \mu \mathrm{g} / \mathrm{mL}$ of methyl gallate.
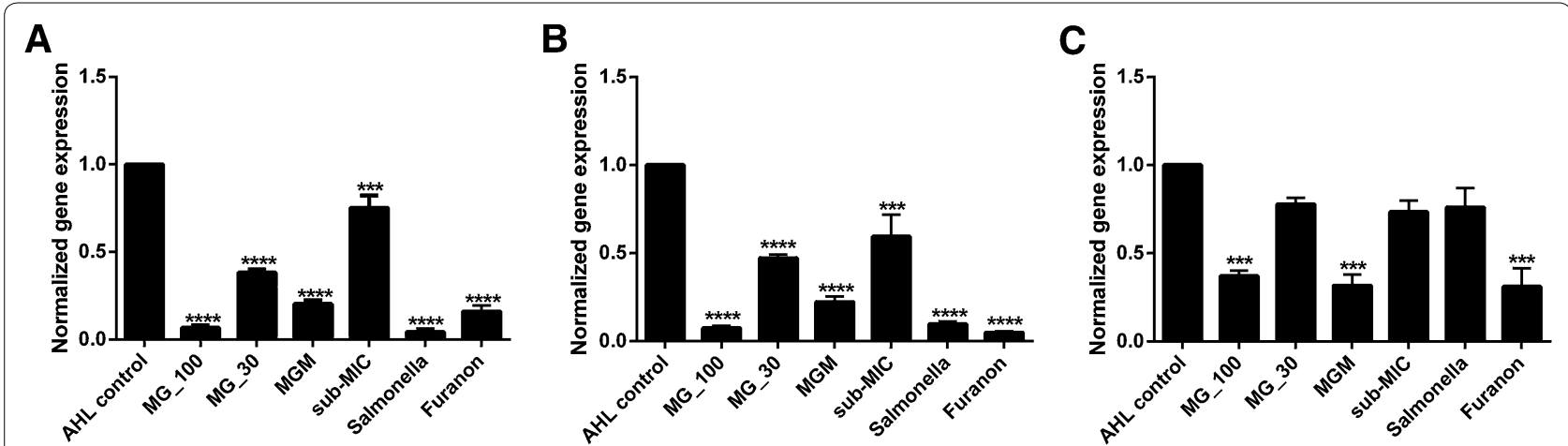

Figure 5 Effect of methyl gallate (MG) on the expression of Salmonella Typhimurium quorum sensing genes (sdiA, srgE, and $r c k$ ). A Effect of MG on srgE expression, $\mathbf{B}$ effect of MG on sdiA expression, and $\mathbf{C}$ effect of MG on rck expression. The genes were activated by $1 \mu \mathrm{mol}$ of $\mathrm{N}$-acetyl homoserine lactone (AHL) and treated with 100 and $30 \mu \mathrm{g} / \mathrm{mL}$ of $\mathrm{MG}$ and its combination with a sub-minimum inhibitory concentration (MIC) of MRB before incubation for $8 \mathrm{~h}$. AHL-control, inoculated with Salmonella Typhimurium in the presence of AHL; MG_100, inoculated with Salmonella Typhimurium in the presence of AHL and $100 \mu \mathrm{g} / \mathrm{mL}$ of NG; MG_30, inoculated with Salmonella Typhimurium in the presence of AHL and $30 \mu \mathrm{g} / \mathrm{mL}$ of MG; MGM, inoculated with Salmonella Typhimurium in the presence of AHL and a combination of sub-MIC of MRB with $30 \mu \mathrm{g} /$ $\mathrm{mL}$ of MG; sub-MIC, inoculated with Salmonella Typhimurium in the presence of AHL and sub-MIC of MRB; Salmonella, inoculated with Salmonella Typhimurium without AHL; Furanon, inoculated with Salmonella Typhimurium in the presence of AHL and $10 \mathrm{mg} / \mathrm{mL}$ of furanone as a positive control. Values indicated are the mean $\pm \operatorname{SEM}\left(n=3 ;{ }^{* * *} P\right.$-value $\left.<0.001\right)$.

To determine the mechanism underlying the adhesion and invasion inhibition, the expression level of $r c k$ gene, which is important for host cell invasion via the zipper mechanism, was evaluated via qRT-PCR. Accordingly, rck was downregulated by $26.7,22.2$ and $68.4 \%$ for bacteria treated with only sub-MIC of MRB, MG alone ( $30 \mu \mathrm{g} /$ $\mathrm{mL}$ ) and MG in combination with sub-MIC of MRB, respectively (Figure $5 \mathrm{C}$ ).
Salmonella invasion in epithelial cells was facilitated upon overexpression of Rac-1 and Cdc42 proteins. Hence, it is essential to determine the effect of MG on these Rho GTPases family members. Their gene expression levels were determined via the invasion assay. rac1 suppression by sub-MIC of MRB alone was $10.3 \%$. Whereas, MG suppressed rac-1 in Caco-2 cells by 56.9 and $71.9 \%$ alone and in combination with sub-MIC of MRB, respectively, which was significantly different 

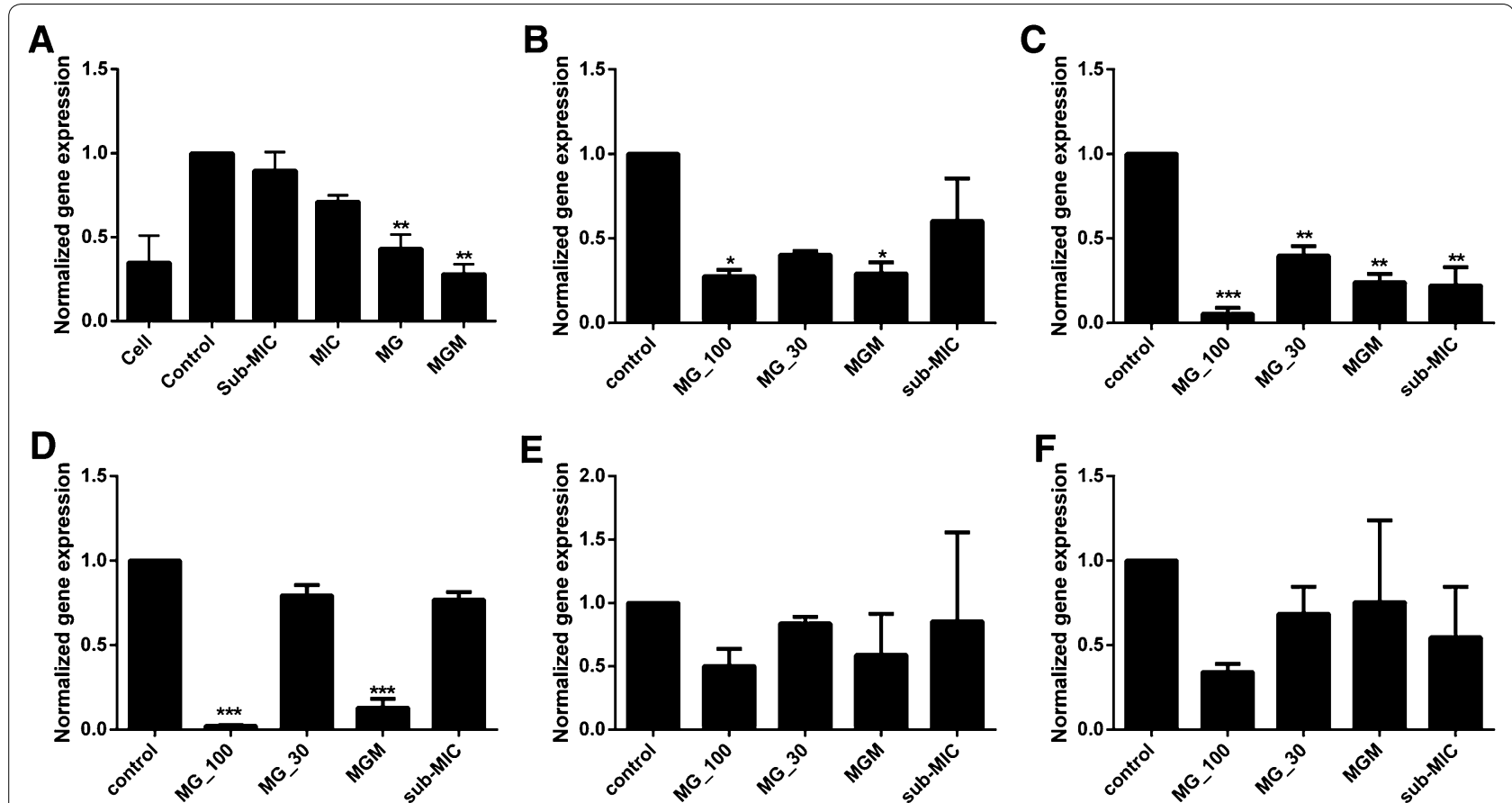

Figure 6 Downregulation of Salmonella Typhimurium virulence genes by methyl gallate (MG). A Effect of MG on rac-1 expression, B effect of MG on cheY expression, $\mathbf{C}$ effect of $M G$ on ompD expression, $\mathbf{D}$ effect of $M G$ on sipB expression, $\mathbf{E}$ effect of $M G$ on lexA expression, and $\mathbf{F}$ effect of MG on ompF expression. Bacteria were cultured with MG at different concentrations and incubated for $13 \mathrm{~h}$ in a non-shaking incubator aerobically at $37^{\circ} \mathrm{C}$. Gene expression levels were quantified via quantitative reverse transcription polymerase chain reaction. Control, inoculated with Salmonella Typhimurium but left untreated; MG__100, inoculated with Salmonella Typhimurium and treated with 100 Mg/mL of MG; MG_30, inoculated with Salmonella Typhimurium and treated with $30 \mathrm{\mu g} / \mathrm{mL}$ of MG; MGM, inoculated with Salmonella Typhimurium and treated with the combination of MG (30 $\mathrm{\mu g} / \mathrm{mL})$ and sub-MIC of MRB; Sub-MIC, inoculated with Salmonella Typhimurium and treated with sub-MIC of MRB. Values indicated are the mean $\pm \operatorname{SEM}(n=3 ; * * *$-value $<0.001)$.

$(P=0.0009)$ from that of the non-treated controls. However, no significant difference was observed in $c d c 42$ gene expression levels (data not shown) (Figure 6A).

In addition, the effect of MG on expression of Salmonella Typhimurium virulence genes essential for invasion and adhesion were assessed via qRT-PCR. The sub-MIC of MRB downregulated the expression of cheY, ompD, $\operatorname{sipB}$, lexA, and ompF by $39.7,77.8,23.1,45.4$ and $14.6 \%$, respectively. MG $(30 \mu \mathrm{g} / \mathrm{mL})$ downregulated cheY, ompD, sipB, lexA, and ompF by 59.6, 60.2, 20.5, 31.4, and $16.2 \%$, respectively. Furthermore, the combination of the same concentration of MG with sub-MIC of MRB downregulated cheY, ompD, sipB, lexA, and ompF by 70.7, 76, 87, 24.6 , and $41.1 \%$, respectively. Gene expression was inhibited in a dose-dependent manner and differed significantly $(P<0.033)$ from the non-treated control groups, except for lexA and ompF genes (Figure 6).

\section{Discussion}

Salmonella Typhimurium causes infections in humans and animals by adhering to host cells. Unlike other bacteria, Salmonella uses two different strategies to invade host cells [8]. Furthermore, drug resistance has emerged as a major public health concern. Currently, drug resistance has extended to the most conserved drugs including fluoroquinolones. Salmonella Typhimurium has developed resistance to MRB and enrofloxacin, which are widely used to treat multi-drug resistant bacteria in the veterinary medicine [15]. Hence, a substitute or combinatorial therapy is critical to limit the rate of infection rate and to reduce the occurrence of drug resistance. Therefore, in this study, we evaluated the antibacterial activity of MG and its mechanism underlying the inhibition of adhesion, invasion, and intracellular survival of Salmonella Typhimurium alone and in combination with MRB.

In this study, MG displayed antibacterial activity against field and laboratory strains (ATCC 14028) of Salmonella Typhimurium. The antibacterial activity of MG has also been reported previously $[16,23]$. This finding is concurrent with reports on multidrug-resistant Shigella spp. and nalidixic acid resistant bacteria [18, 27]. However, no cytotoxicity and antibacterial activity of MG was observed at $30 \mu \mathrm{g} / \mathrm{mL}$, showing that this concentration had no effect on mammalian cells and bacterial growth. 
Thus, we used this concentration to determine the effect of MG on the bacterial adhesion, invasion, and intracellular survival.

Pathogenic bacterial adhesion to host surfaces is an essential step in the pathogenesis of almost all infections, defining tissue tropism to specific surface receptors and resistance to physical elimination of extracellular fluids at mucosal sites [28]. Hence, adhesion plays a significant role in bacterial survival and replication. In this study, we reported that MG significantly reduced the adherence of Salmonella Typhimurium to host cell surfaces, which was further reduced in combination with the sub-MIC of MRB. Prevention of bacterial adhesion is a critical step to interfere with bacterial pathogenesis and colonization at the early phase of infection [29].

Once adhered to the host cell surface, bacteria penetrate cells via attachment with surface receptors or by direct translocation of bacterial proteins into the host cell. Invasion of Salmonella into host cells is critical for its survival and establishment of infection in the host. Salmonella Typhimurium is specialized in using the "trigger" and the "zipper" mechanisms to invade cells, using their specialized Salmonella pathogenicity island-1 type III secretion system (SPI-1 T3SS) [7, 8]. Our findings indicate that MG can inhibit Salmonella invasion both in intestinal epithelial cells and macrophages when administered alone and in combination with MRB. This inhibitory effect is critical in reducing infection and diseases due to Salmonella Typhimurium.

MG inhibits bacterial invasion through various potential mechanisms. Bacterial motility is one of the phenomena that increases the rate of bacterial invasion [30]. Hence, inhibiting bacterial motility could reduce bacterial invasion. Our results indicated that motility of Salmonella Typhimurium was suppressed by MG alone and in combination with MRB. This reduction might probably result from the downregulation of the cheY gene by MG. CheY is a response regulator of the chemotaxis machinery, which regulates flagellar rotation of a motile bacterium including Salmonella [31]. CheY has high affinity for a switch component, FliM, at the flagellar motor, which alters flagellar rotation from the counterclockwise to the clockwise direction [32]. Suppression of cheY prevents directional switching of flagellar motors and renders the bacteria non-chemotactic, which further reduces bacterial adhesion and invasion. Furthermore, MG affects the proton motive force and ATP synthesis in Gram-negative bacteria, which is required for the synthesis and expression of motility- and other related genes [18].

Along with motility, penetration of Salmonella into the mucosal tissues of their hosts is mediated by various genes expressed from SPI-1 [33]. Furthermore, QS genes play a significant role in bacterial invasion of host cells. Hence, its inhibition reduces invasion of Salmonella, which in turn decrease its virulence [25]. In this study, we have shown that MG downregulated Salmonella Typhimurium QS genes (sdiA and srgE). Salmonella may perform QS for effective invasion under suitable conditions. In Salmonella Typhimurium, sdiA and srgE are regulated by the transcription factor LsrR. LsrR represses InvF expression and transcription of the InvF-regulated genes within SPI-1 and flagella genes. Hence, it impairs bacterial invasion of mammalian cells. In addition, when Salmonella approach a sufficient population level under a specific condition, QS might modulate the expression of virulence factors [34]. Concurrent with these suggestions, the inhibition of QS genes by MG and its combination with MRB could downregulate Salmonella virulence genes, which are specifically important for adhesion and invasion of cells.

MG suppressed $r c k$, which is important in the receptor-mediating (zipper) mechanism of Salmonella invasion and entry into cells [7]. Downregulation of this gene reduces the invasion of Salmonella Typhimurium significantly. In Escherichia coli, overexpression of Rck enables the non-invasive bacterial adhere and invasion of fibroblastic cells [35]. The downregulation of $r c k$ might also be caused by the suppression of the Salmonella QS genes, specifically sdiA by MG. This might suggest that MG inhibits Salmonella invasion by blocking the zipper mechanism of invasion.

rac-1, an inducer of cytoskeletal remodeling [25], was also downregulated during treatment with MG after Salmonella Typhimurium invasion. The downregulation of rac-1 genes of the host cell, whose activation is critical because it enhances the accumulation of actin filaments at sites of bacterial entry and a necessary step for bacterial invasion, is essential in inhibiting invasion. Rac-1 has also indicated to have a role in the "zipper" mechanism of invasion in uropathogenic E. coli $[36,37]$. This result strongly supports our finding in that MG follows the same mechanism to inhibit invasion of Salmonella Typhimurium in the intestinal epithelial cells.

The inhibitory activity of MG alone or in combination with MRB was evident from the downregulation of $o m p D$, a porin protein. Hence, the downregulation of ompD could be another factor for the reduction of adhesion and invasion of Salmonella Typhimurium in mammalian cells. This is concurrent with the findings of Ipinza et al. [38] who described the role of ompD in Salmonella invasion and intracellular survival in RAW264.7 cells and BALBc mice. The significance of ompD in adherence of Salmonella Typhimurium was also indicated in human monocytes and intestinal epithelial cells [39]. Suppression of the outer membrane protein genes 
$o m p D$ and $o m p F$ was associated with the disruption of the outer membrane of Salmonella Typhimurium by MG, which can probably affect both proton motive force and ATP synthesis, resulting in disorganizing the bacterial membrane [18].

Salmonella expresses SPI-1 virulence genes to invade host cells. SipB is one of the effector proteins of SPI-1 T3SS, which facilitates Salmonella entry into the host cell [40]. $\operatorname{sip} B$ was downregulated by MG in our study. Although it did not affect the growth of Salmonella, its suppression significantly decreased adherence, invasion, and virulence [41]. SipB also affects membrane fluidity and alters bacterial osmotolerance, thereby influencing membrane integrity [42]. This can potentially prevent Salmonella from penetrating host cells.

In conclusion, in this study, we have reported the in vitro effects of MG in preventing bacterial adherence and entrance and intracellular survival in the host cells, either alone or in combination with MRB, a widely used antibiotic in veterinary medicine. MG downregulated QS genes in Salmonella infections and suppressed the rac-1 gene of the host cells. This may suggest that MG might interfere with the zipper mechanism of Salmonella Typhimurium to inhibit its invasion. MG also downregulated the virulence genes of Salmonella Typhimurium, which are critical for invasion of host cells. This activity of MG could demonstrate its ability to limit pathogenic bacterial infections and diseases of animals, specifically diseases caused by Salmonella Typhimurium. Furthermore, its effectiveness in combination with antimicrobials, such as MRB, against both susceptible and drug resistant bacterial strains revealed its paramount significance in combating antimicrobial resistance. However, further in vivo investigation on the clinical output of MG alone and in combination with other antibacterial agents is warranted.

\section{Additional file}

Additional file 1. Primers used for quantitative reverse transcription polymerase chain reaction.

\section{Abbreviations}

AHL: N-acyl homoserine lactone; ATP: adenosine triphosphate; CFU: colonyforming unit; LB: Luria Bertani; MG: methyl gallate; MIC: minimum inhibitory concentration; MOI: multiplicity of infection; MRB: marbofloxacin; QS: quorum sensing; SPI: Salmonella pathogenicity island; T3SS: type three section system.

\section{Competing interests}

The authors declare that they have no competing interests.

\section{Authors' contributions}

BTB involved in conception, design, acquisition of data, analysis, interpretation, drafting and critically revising the manuscript; NHP, MAH and SJL involved in some of the experiments and reviewed the manuscript; SCP conceived the study, analyzed the data and approved the final version of the manuscript. All authors read and approved the final manuscript.

\section{Acknowledgements}

The authors would like to thank all members of the laboratory of veterinary pharmacokinetics and pharmacodynamics, College of veterinary Medicine, Kyungpook National University for their support during these studies.

\section{Author details \\ ${ }^{1}$ Laboratory of Veterinary Pharmacokinetics and Pharmacodynamics, College of Veterinary Medicine, Kyungpook National University, Bukgu, Daegu 41566, South Korea. ${ }^{2}$ Veterinary Drugs and Biologics Division, Animal and Plant Quarantine Agency, Gimcheon 39660, South Korea.}

\section{Funding}

This study was supported in part by the National Research Foundation of Korea (NRF) funded by the Ministry of Education (2016R1A2B4013507). This manuscript is based on part of the first author's doctoral dissertation from Kyungpook National University.

\section{Publisher's Note}

Springer Nature remains neutral with regard to jurisdictional claims in published maps and institutional affiliations.

Received: 2 August 2018 Accepted: 23 September 2018

Published online: 04 October 2018

\section{References}

1. Viswanathan VK, Hodges K, Hecht G (2009) Enteric infection meets intestinal function: how bacterial pathogens cause diarrhoea. Nat Rev Microbiol 7:110-119

2. Ribet D, Cossart P (2015) How bacterial pathogens colonize their hosts and invade deeper tissues. Microbes Infect 17:173-183

3. Haraga A, Ohlson MB, Miller SI (2008) Salmonellae interplay with host cells. Nat Rev Microbiol 6:53-66

4. Jantsch J, Chikkaballi D, Hensel M (2011) Cellular aspects of immunity to intracellular Salmonella enterica. Immunol Rev 240:185-195

5. Thiennimitr P, Winter SE, Bäumler AJ (2012) Salmonella, the host and its microbiota. Curr Opin Microbiol 15:108-114

6. Stecher B, Maier L, Hardt W-D (2013) "Blooming"; in the gut: how dysbiosis might contribute to pathogen evolution. Nat Rev Microbiol 11:277-284

7. Rosselin M, Virlogeux-Payant I, Roy C, Bottreau E, Sizaret PY, Mijouin L, Germon P, Caron E, Velge P, Wiedemann A (2010) Rck of Salmonella enterica, subspecies enterica serovar Enteritidis, mediates zipper-like internalization. Cell Res 20:647-664

8. Velge P, Wiedemann A, Rosselin M, Abed N, Boumart Z, Chaussé AM, Grépinet O, Namdari F, Roche SM, Rossignol A, Virlogeux-Payant I (2012) Multiplicity of Salmonella entry mechanisms, a new paradigm for Salmonella pathogenesis. Microbiologyopen 1:243-258

9. Friebel A, Ilchmann H, Aepfelbacher M, Ehrbar K, Machleidt W, Hardt WD (2001) SopE and SopE2 from Salmonella typhimurium activate different sets of RhoGTPases of the host cell. J Biol Chem 276:34035-34040

10. Patel JC, Galán JE (2006) Differential activation and function of Rho GTPases during Salmonella-host cell interactions. J Cell Biol 175:453-463

11. Campoccia D, Montanaro L, Arciola CR (2013) A review of the clinical implications of anti-infective biomaterials and infection-resistant surfaces. Biomaterials 34:8018-8029

12. Cinquin B, Maigre L, Pinet E, Chevalier J, Stavenger RA, Mills S, Réfrégiers M, Pagès J (2016) Microspectrometric insights on the uptake of antibiotics at the single bacterial cell level. Sci Rep 5:17968

13. Tamma PD, Cosgrove SE, Maragakis LL (2012) Combination therapy for treatment of infections with gram-negative bacteria. Clin Microbiol Rev 25:450-470

14. Hartog E, Menashe O, Kler E, Yaron S (2010) Salicylate reduces the antimicrobial activity of ciprofloxacin against extracellular Salmonella enterica serovar Typhimurium, but not against Salmonella in macrophages. J Antimicrob Chemother 65:888-896 
15. Lee S-J, Park N-H, Mechesso AF, Lee K-J, Park S-C (2017) The phenotypic and molecular resistance induced by a single-exposure to sub-mutant prevention concentration of marbofloxacin in Salmonella Typhimurium isolates from swine. Vet Microbiol 207:29-35

16. Schoevers EJ, van Leengoed LA, Verheijden JH, Niewold TA (1999) Effects of enrofloxacin on porcine phagocytic function. Antimicrob Agents Chemother 43:2138-2143

17. Xie S, Yang F, Tao Y, Chen D, Qu W, Huang L, Liu Z, Pan Y, Yuan Z (2017) Enhanced intracellular delivery and antibacterial efficacy of enrofloxacinloaded docosanoic acid solid lipid nanoparticles against intracellular Salmonella. Sci Rep 7:41104

18. Acharyya S, Sarkar P, Saha DR, Patra A, Ramamurthy T, Bag PK (2015) Intracellular and membrane-damaging activities of methyl gallate isolated from Terminalia chebula against multidrug-resistant Shigella spp. J Med Microbiol 64:901-909

19. Ozcan T, Akpinar-Bayizit A, Yilmaz-Ersan L, Delikanli B (2014) Phenolics in human health. Int J Chem Eng Appl 5:393-396

20. Hossain MA, Lee S-J, Park N-H, Mechesso AF, Birhanu BT, Kang JW, Reza MA, Suh J-W, Park S-C (2017) Impact of phenolic compounds in the acyl homoserine lactone-mediated quorum sensing regulatory pathways. Sci Rep 7:10618

21. Yong Y-C, Zhong J-J (2012) Impacts of quorum sensing on microbial metabolism and human health. In: Advances in biochemical engineering/biotechnology. pp 25-61

22. Wu J, Pugh R, Laughlin RC, Andrews-Polymenis H, McClelland M, Bäumler AJ, Adams LG (2014) High-throughput assay to phenotype Salmonella enterica Typhimurium association, invasion, and replication in macrophages. J Vis Exp 90:e51759

23. Johnson MB, Criss AK (2013) Fluorescence microscopy methods for determining the viability of bacteria in association with mammalian cells. J Vis Exp https://doi.org/10.3791/50729

24. Clemmer KM, Bonomo RA, Rather PN (2011) Genetic analysis of surface motility in Acinetobacter baumannii. Microbiology 157:2534-2544

25. Choi J, Shin D, Ryu S (2007) Implication of quorum sensing in Salmonella enterica Serovar typhimurium virulence: the luxS gene is necessary for expression of genes in pathogenicity island 1. Infect Immun 75:4885-4890

26. Li G, Yan C, Xu Y, Feng Y, Wu Q, Lv X, Yang B, Wang X, Xia X (2014) Punicalagin inhibits Salmonella virulence factors and has anti-quorum-sensing potential. Appl Environ Microbiol 80:6204-6211

27. Choi J-G, Kang O-H, Lee Y-S, Oh Y-C, Chae H-S, Jang H-J, Shin D-W, Kwon D-Y (2009) Antibacterial activity of methyl gallate isolated from Galla Rhois or carvacrol combined with nalidixic acid against nalidixic acid resistant bacteria. Molecules 14:1773-1780

28. Connell H, Hedlund M, Agace W, Svanborg C (1997) Bacterial attachment to uro-epithelial cells: mechanisms and consequences. Adv Dent Res 11:50-58
29. Klemm P, Vejborg RM, HancockV (2010) Prevention of bacterial adhesion. Appl Microbiol Biotechnol 88:451-459

30. Khoramian-Falsafi T, Harayama S, Kutsukake K, Pechère JC (1990) Effect of motility and chemotaxis on the invasion of Salmonella typhimurium into HeLa cells. Microb Pathog 9:47-53

31. Guhaniyogi J, Wu T, Patel SS, Stock AM (2008) Interaction of CheY with the C-terminal peptide of CheZ. J Bacteriol 190:1419-1428

32. Wolanin PM, Webre DJ, Stock JB (2003) Mechanism of phosphatase activity in the chemotaxis response regulator CheY. Biochemistry 42:14075-14082

33. Galán JE (2001) Salmonella interactions with host cells: type III secretion at work. Annu Rev Cell Dev Biol 17:53-86

34. Choi J, Shin D, Kim M, Park J, Lim S, Ryu S (2012) LsrR-mediated quorum sensing controls invasiveness of Salmonella typhimurium by regulating SPI-1 and flagella genes. PLoS One 7:e37059

35. Heffernan EJ, Wu L, Louie J, Okamoto S, Fierer J, Guiney DG (1994) Specificity of the complement resistance and cell association phenotypes encoded by the outer membrane protein genes rck from Salmonella Typhimurium and ail from Yersinia enterocolitica. Infect Immun 62:5183-5186

36. Martinez JJ, Hultgren SJ (2002) Requirement of Rho-family GTPases in the invasion of type 1-piliated uropathogenic Escherichia coli. Cell Microbiol 4:19-28

37. Duncan MJ, Li G, Shin J-S, Carson JL, Abraham SN (2004) Bacterial penetration of bladder epithelium through lipid rafts. J Biol Chem 279:18944-18951

38. Ipinza F, Collao B, Monsalva D, Bustamante VH, Luraschi R, Alegría-Arcos M, Almonacid DE, Aguayo D, Calderón IL, Gil F, Santiviago CA, Morales EH, Calva E, Saavedra CP (2014) Participation of the Salmonella OmpD porin in the infection of RAW264.7 macrophages and BALB/c Mice. PLoS One 9:e111062

39. Hara-Kaonga B, Pistole TG (2004) OmpD but not OmpC is involved in adherence of Salmonella enterica serovar Typhimurium to human cells. Can J Microbiol 50:719-727

40. Patel JC, Hueffer K, Lam TT, Galán JE (2009) Diversification of a Salmonella virulence effector protein function by ubiquitin-dependent differential localization. Cell 137:283-294

41. Chen S, Zhang C, Liao C, Li J, Yu C, Cheng X, Yu Z, Zhang M, Wang Y (2015) Deletion of invasion protein $B$ in Salmonella enterica serovar typhimurium influences bacterial invasion and virulence. Curr Microbiol 71:687-692

42. Asakura H, Ekawa T, Sugimoto N, Momose Y, Kawamoto K, Makino S, Igimi S, Yamamoto S (2012) Membrane topology of Salmonella invasion protein SipB confers osmotolerance. Biochem Biophys Res Commun 426:654-658
Ready to submit your research? Choose BMC and benefit from:

- fast, convenient online submission

- thorough peer review by experienced researchers in your field

- rapid publication on acceptance

- support for research data, including large and complex data types

- gold Open Access which fosters wider collaboration and increased citations

- maximum visibility for your research: over 100M website views per year

At $\mathrm{BMC}$, research is always in progress.

Learn more biomedcentral.com/submissions 